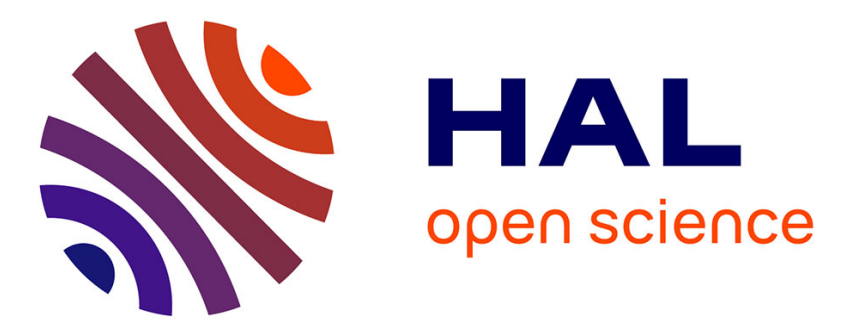

\title{
Figures of merit of a small antenna in cluttered IR-UWB wireless sensor networks applications
}

Hamadache Zemmour, Antoine Diet, Genevieve Baudoin, Jocelyn Fiorina

\section{To cite this version:}

Hamadache Zemmour, Antoine Diet, Genevieve Baudoin, Jocelyn Fiorina. Figures of merit of a small antenna in cluttered IR-UWB wireless sensor networks applications. IEEE International Conference on Ultra-Wideband (ICUWB 2014), Sep 2014, Paris, France. pp.141 - 146, 10.1109/ICUWB.2014.6958966 . hal-01104662

HAL Id: hal-01104662

https://hal-centralesupelec.archives-ouvertes.fr/hal-01104662

Submitted on 18 Jan 2015

HAL is a multi-disciplinary open access archive for the deposit and dissemination of scientific research documents, whether they are published or not. The documents may come from teaching and research institutions in France or abroad, or from public or private research centers.
L'archive ouverte pluridisciplinaire HAL, est destinée au dépôt et à la diffusion de documents scientifiques de niveau recherche, publiés ou non, émanant des établissements d'enseignement et de recherche français ou étrangers, des laboratoires publics ou privés. 


\section{Figures Of Merit Of a Small Antenna in Cluttered IR-UWB Wireless Sensor Networks Applications}

\author{
Hamadache ZEMMOUR, \\ Geneviève BAUDOIN \\ Université Paris-Est, ESYCOM (EA2552), ESIEE-Paris \\ 2 Bd Blaise Pascal, BP 99, Noisy le Grand, France \\ hamadache.zemmour@esiee.fr \\ genevieve.baudoin@esiee.fr
}

\author{
Antoine DIET \\ L2S/DRE UMR 8506 - LGEP UMR 8507 \\ Plateau du Moulon, F-91192 Gif Sur Yvette, France \\ antoine.diet@u-psud.fr \\ Jocelyn FIORINA \\ SUPELEC, département Télécommunications \\ Plateau du Moulon, F-91192 Gif Sur Yvette, France \\ Jocelyn.fiorina@supelec.fr
}

\begin{abstract}
This work focuses on UWB for cluttered wireless sensor network (WSN) applications, especially antennas design. In this paper, we present a novel planar small ultra-wideband (UWB) micro-strip fed antenna, for IR-UWB. Cluttered WSN are difficult cases for communications, implying the antenna to be adapted to the communication channel. The first consideration is the path loss compensation hypothesis. The designed antenna has a small size of $20 \times 20 \times 0.8 \mathrm{~mm}^{3}$, and an omnidirectional radiation pattern over the frequency band considered (6-8.5 GHz). A comprehensive characterization of the antenna is done in both frequency and time domain. Thus, different path loss orders are considered and two signal pulses are used. The effect of channel path loss is discussed and the antenna transfer function is determined. Return loss and radiation pattern are depicted and completed with the isotropy factor. The gain increases with frequency, providing a quasiconstant free space transmission channel transfer function. Time domain analysis, via Fidelity factor and pulse width Stretch Ratio, is done for the both pulses and for the different path loss orders. Such Figures of Merit (FoM) are discussed in function of the path-loss order, which is a simple modelization of cluttered WSN channels (reference cases).
\end{abstract}

Keywords-impulse radio ultrawideband (IR-UWB); wireless sensor network (WSN); UWB antenna; antenna transfer function; fidelity.

\section{CONSIDERATIONS FOR IR-UWB CLUTTERED CHANNEL}

Impulse Radio Ultra-WideBand technology (IR-UWB) is of great interest in communication, localization systems and wireless sensors network because it has the potential advantage of spread spectrum immunity and low power consumption. Consequently, this technology is highly focusing on small transceiver integrating as possible low cost small antennas. The Federal Communication Commission (FCC) allocated the frequency band 3.1 to $10.6 \mathrm{GHz}$ for the UWB in 2002[1]. On February 2007, the commission of the European Communities released a decision on using $(6-8.5 \mathrm{GHz})$ radio spectrum band for UWB technology [2]. Several UWB transponders for Wireless Sensors Networks (WSN) applications have been proposed [3][4]. The UWB WSN system requires the conception of UWB transmitter and receiver with dedicated antennas due to the specificity of the propagation channel and size constraints. In our case, the Network is supposed to be composed by emitting and receiving nodes, implying the same antenna to be switched (size reduction).

The main and basic requirements for such antennas are a small size, omnidirectional pattern, low cost, a huge operational bandwidth and non-dispersive behavior [5][6]. Furthermore, the simplified channel transfer function is decreasing with increasing frequency at first glance [7][8][9][10], depending on the path loss attenuation factor. Therefore, if the antenna transfer function increases with frequency (for example "F-gain" antenna [10] which presents a linear increasing gain with frequency), it may compensate this dependency and limits the signal distortion (fidelity increased) which allows getting better transmission [5][9][11][12]. Fig.1 illustrates how we can match this consideration with the constraint of using only one antenna [9][10].

This consideration is subject to numerous modification and proposals for channel modelization, in UWB quasi-free space and LOS configurations [13]. In cluttered WSN, the different UWB nodes are supposed to be transceivers as simple as possible with minimum size and low-cost realization. The difficulty of the communication (RF link) is due to the great attenuation of materials making the cluttered nature of the channel. Consequently no line of sight is possible and a high influence of the materials and geometry are present. These characteristics made the frequency an important parameter of the channel influence. We started the antenna design optimization with a simple model of attenuation $\left(\mathrm{n}^{\text {th }}\right.$ order path loss attenuation).

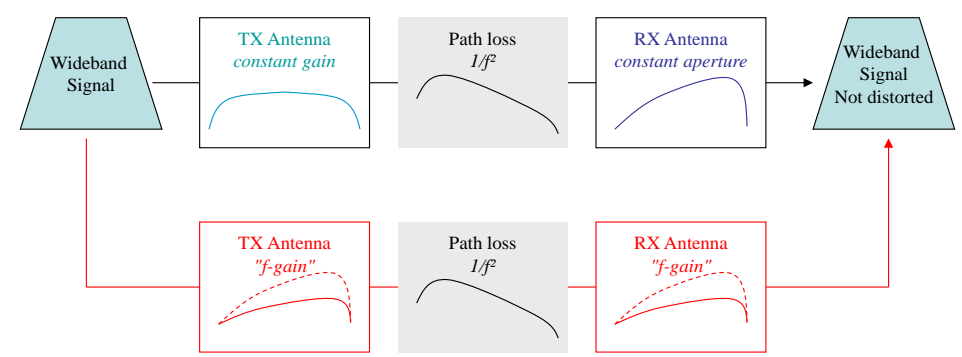

Fig. 1. F gain antenna principle 
In these conditions, a small antenna for dedicated IR-UWB transceiver is designed and detailed in part II. Following parts quantify its bandwidth, Isotropy factor, Fidelity factor (F), Stretch Ratio (SR) [8] and other figures of merit for WSN application. The time domain analysis completes the frequency domain results by studying the effect of the antenna on the transmitted signal. For investigating the time domain transmission of the antenna, a transmitted signal waveform has to be defined. This waveform can be theoretically or based on the technology possibilities (Gaussian filtered pulse or fast rectangular pico-pulse) for better accuracy with possible transmitter realization. The time domain analysis consists in studying the effect of the antennas (emission and reception) combined with the channel on the transmitted signal. Then, a comparison is done between transmitted signal $v_{t}(t)$ and received signal $v_{r}(t)$, to evaluate the distortion effect. Two pulses, are used to achieve this analysis, the frequencytranslated Gaussian voltage waveform $v_{t g}(t)$, and the rectangular voltage waveform $v_{t r}(t)$, given by:

$$
\begin{gathered}
v_{t g}(t)=k e^{-\alpha t^{2}} \cos \left(2 \pi f_{c} t\right) \\
v_{t r}(t)=\left\{\begin{array}{lr}
k \cos \left(2 \pi f_{c} t\right) & -\frac{T}{2}<t<\frac{T}{2} \\
0 & |t| \geq \frac{T}{2}
\end{array}\right.
\end{gathered}
$$

Where $k$ is the maximum amplitude, $\alpha$ and $T$ are parameters determining the width of the corresponding pulses in the time domain, and $f_{c}$ is the center frequency. The transmitted and received impulse signals are illustrated in part III.

\section{A SMALL ANTENNA FOR IR-UWB WSN}

In this part, we describe the small "F-gain" UWB antenna for IR-UWB WSN, dedicated to the European regulated frequency range $(6-8.5 \mathrm{GHz})$. The design is based on modified rectangular shaped patch, with a $50 \Omega$-micro-strip feed line, and a square ground plane with a wide ellipse shaped slot. Slots and parasitic element are added to improve the antenna performances and customize the frequency dependence of the gain. The performances of the presented antenna fulfill the UWB WSN antenna requirements.

The geometry of the studied antenna and the realized prototype are shown in Fig. 2. It is based on a modified rectangular radiator, with two half elliptical shapes at its horizontal edges and a central H-slot, introducing some design degrees of freedom. The radiator patch is fed by a $50 \Omega$ microstrip line. The ground plane of the antenna consists of a rectangular patch with a wide slot, similar in its shape to the radiator, a small $\mathrm{T}$-slot and an elliptical parasitic patch. The slots and the parasitic element are added to improve and satisfy the performance requirements of the small sized monopole antenna [6][9]. The performances of the antenna depend on its different geometric parameters. At low frequencies, the operating of the antenna critically depends on its lateral length.
This length fixes the lower edge of the operating bandwidth. Then, an optimization approach based on the tradeoff between miniaturization and operating bandwidth is considered. The simulation was performed using CST Microwave Studio. The antenna prototype is designed on low-cost substrate with 0.8 $\mathrm{mm}$ thickness and relative dielectric constant 3.3. A mandatory parametric study was done to obtain the optimum structure, fulfilling the system requirements. Optimal dimensions (listed in Fig.2.a) of the proposed antenna are given in TABLE I.

The simulated return loss of the antenna, shown in Fig. 3, is less than $-10 \mathrm{~dB}$ over a wide frequency band $(4.2-12.4 \mathrm{GHz})$, with nearly linear phase (with a slope of $-49^{\circ} / \mathrm{GHz}$ ) which minimizes the dispersion of the transmitted pulse signal. The antenna bandwidth $(8 \mathrm{GHz})$ is much larger than the UWB band considered $(6-8.5 \mathrm{GHz})$, and then it can be used for other UWB applications, since its UWB characteristics are verified over the entire $(8 \mathrm{GHz})$ band.

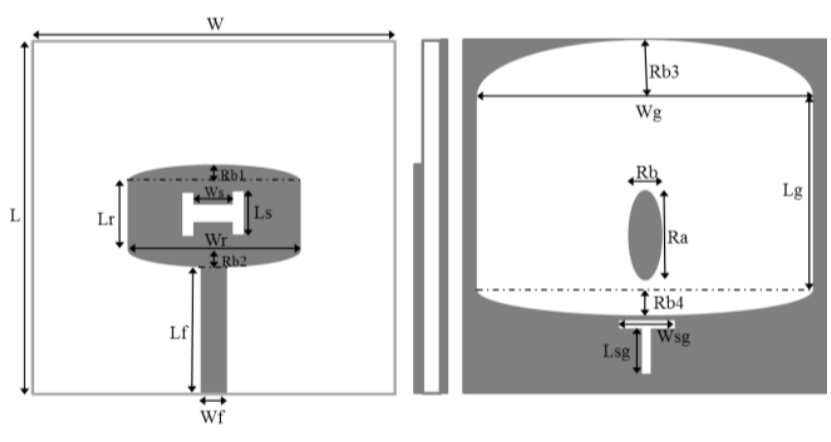

$-\mathrm{a}-$

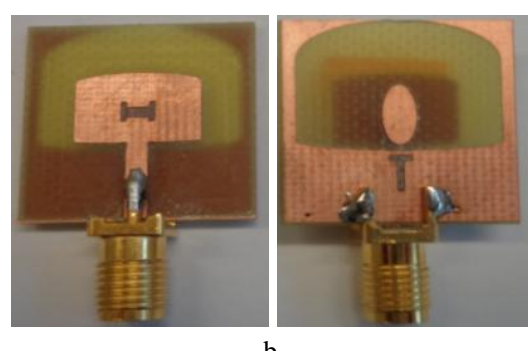

-b-

Fig. 2. The proposed UWB antenna: a-geometry, b-prototype.

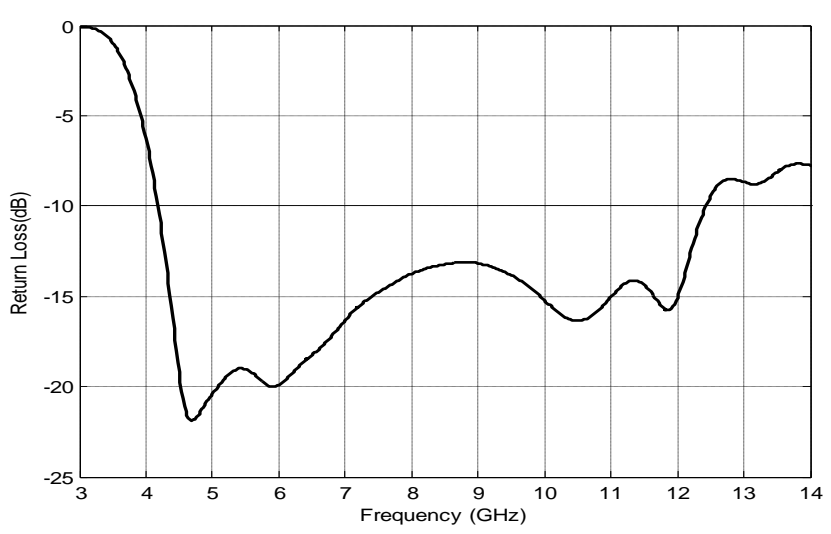

Fig. 3. Return loss of the proposed antenna. 
The antenna radiation patterns in the E-plane and H-plane, at 5, 7.25 and $10 \mathrm{GHz}$, are depicted in Fig. 4. These results clearly expose the omnidirectional behavior of the antenna over the operational bandwidth. The antenna presents a peak gain of $3.26 \mathrm{dBi}$ at $5 \mathrm{GHz}, 3.99 \mathrm{dBi}$ at $7.25 \mathrm{GHz}$ and $4.04 \mathrm{dBi}$ at $10 \mathrm{GHz}$. The efficiency over these three points is about $95 \%$.

The radiation pattern properties can be complementary studied by the Isotropic factor $\mathrm{I}_{\mathrm{x}}$ defined in [11] as the solid angle proportion (ratio with isotropic $4 \pi$ str.) defined by the radiation pattern in function of a directivity level. In fact, this factor corresponds to the area where the radiated power level is less than $\mathrm{x} \mathrm{dBi}$. It is defined at one frequency and for a reference level $\mathrm{x}$, in $\mathrm{dBi}$. The lower the isotropic factor $\mathrm{I}_{\mathrm{x}}$, the better the antenna for isotropy considerations.

The factor $I_{x}$ is given by:

$$
\begin{gathered}
\left.\mathbf{I}_{\mathrm{x}[\mathrm{dBi}}\right]=\sum_{\mathrm{n}}^{\substack{\text { N radiation } \\
\text { pattern areas }}} \mathbf{I}_{\mathrm{x}}^{\mathrm{n}} \\
\mathrm{I}_{\mathrm{x}}^{\mathrm{n}}=\left|\frac{1}{4 \pi} \int_{\theta_{\min (x)}^{\mathrm{n}}}^{\theta_{\max (\mathrm{x})}^{\mathrm{n}}} \int_{\varphi_{\min (\mathrm{x})}^{\mathrm{n}}}^{\varphi_{\max (\mathrm{x})}^{\mathrm{n}}} \mathrm{d} \theta \cos \varphi \mathrm{d} \varphi\right| \\
\mathbf{I}_{\mathrm{x}}^{\mathrm{n}}=\frac{\left|\theta_{\max (\mathrm{x})}^{\mathrm{n}}-\theta_{\min (\mathrm{x})}^{\mathrm{n}}\right|\left|\sin \left(\varphi_{\min (\mathrm{x})}^{\mathrm{n}}\right)-\sin \left(\varphi_{\max (\mathrm{x})}^{\mathrm{n}}\right)\right|}{4 \pi}
\end{gathered}
$$

The omnidirectional behavior of the antenna can be verified by computing the $\mathrm{I}_{\mathrm{x}}$ factor. Fig. 5 displays the Isotropic factor $I_{x}$ versus frequency, for different levels: $0,-1,-3$ and $-6 \mathrm{dBi}$. From the $-3 \mathrm{dBi}$ level curve, it is noticed that the area of radiated power less than this level is less than $1.68 \%$ of the total area when the frequency is under $7 \mathrm{GHz}$, which means that the antenna radiates more than $-3 \mathrm{dBi}$ over $98.32 \%$ of directions. For the $7 \mathrm{GHz}$ to $10 \mathrm{GHz}$ band, it is noted that the antenna radiates more than $-6 \mathrm{dBi}$ over all the directions. From these results, the omnidirectional radiation behavior of the antenna is confirmed.

\section{RF LINK ANALYSIS}

\section{A. Frequency domain}

Two identical antennas are considered in free space environment, as shown in Fig.6. The transmitting antenna (Port 1) and receiving antenna (Port 2) were located in the same plane, at a distance (d) of $30 \mathrm{~cm}$ in LOS (Line Of Sight). The $\mathrm{S}_{21}$ result represents the transfer function of the system, composed by the two identical antennas and the ideal free space channel, in the azimuthal plane. The transfer function of the system $H_{s}(f)$ can be written as[5][14]

$$
H_{s}(f)=H_{t}(f, \theta, \varphi) H_{c}(f, d) H_{r}(f, \theta, \varphi)
$$

TABLE I. OPTIMIZED ANTENNA PARAMETERS (mm)

\begin{tabular}{|c|c|c|c|c|c|c|c|c|}
\hline L & W & Lf & Wf & Lr & Wr & Ls & Ws & Rb1 \\
\hline 20 & 20 & 7.65 & 1.85 & 6 & 11 & 2 & 2 & 1 \\
\hline Rb2 & Rb3 & Rb4 & Ra & Rb & Lg & Wg & Lsg & Wsg \\
\hline 0.2 & 4 & 1 & 3 & 1.5 & 8 & 17.8 & 3 & 2 \\
\hline
\end{tabular}
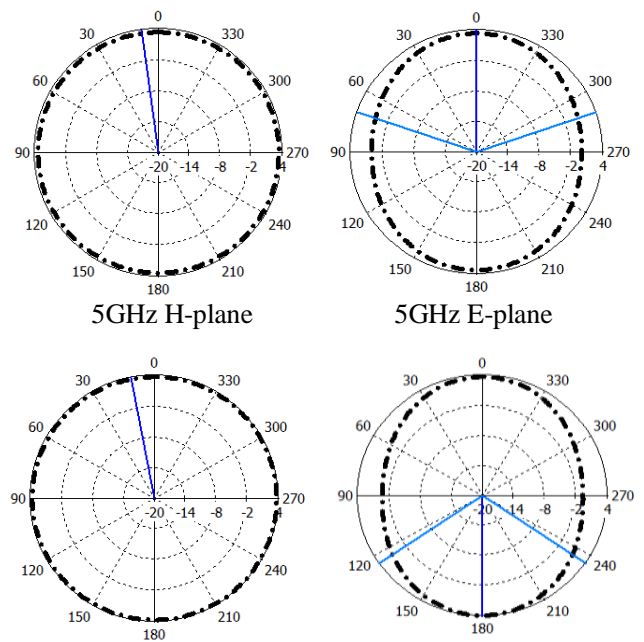

7.25GHz H-plane
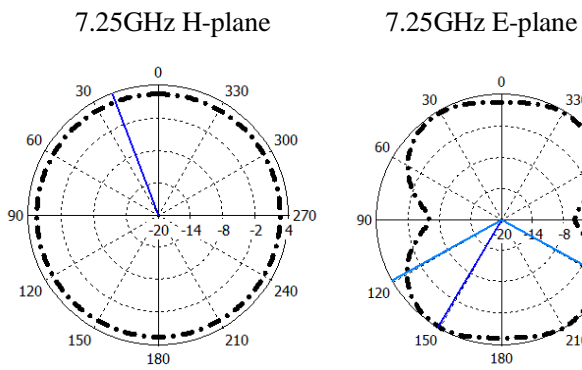

$10 \mathrm{GHz} \mathrm{H}$-plane

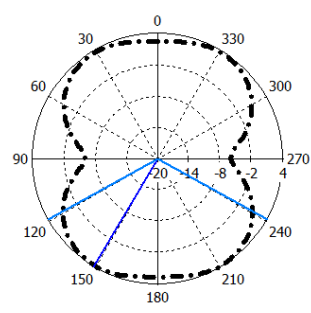

$10 \mathrm{GHz}$ E-plane

Fig. 4. E-plane / H-plane radiation patterns at 5,7.25 and 10GHz.

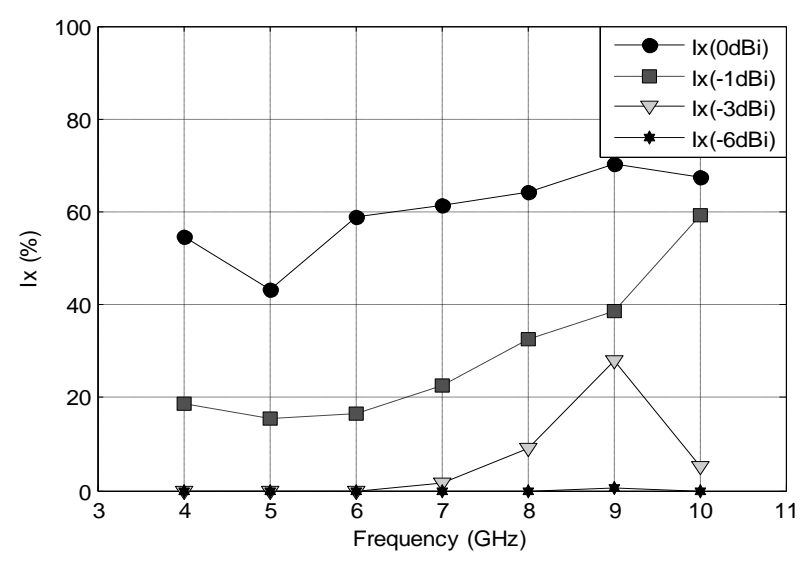

Fig. 5. Isotropic factor $\mathrm{Ix}(\mathrm{x}=0,-1,-3$ and $-6 \mathrm{dBi})$. 
where

$$
H_{c}(f, d)=\frac{c}{4 \pi f d} e^{-j \frac{2 \pi f}{c} d}
$$

is the free space transfer function for electric field representation. $H_{t}(f, \theta, \varphi)$ and $H_{r}(f, \theta, \varphi)$ are the transmitting and receiving antennas transfer functions toward $\theta$ and $\varphi$ directions.

In this work, transmitting and receiving antennas are identical and aligned, then their magnitude transfer functions can be given as [5][14]

$$
\left|H_{t}(f, \theta, \varphi)\right|=\left|H_{r}(f, \theta, \varphi)\right|=\sqrt{\frac{\left|H_{s}(f)\right|}{\left|H_{c}(f, d)\right|}}
$$

Path-losses of different orders, corresponding to different mediums, $H_{n, k}(f, d)$, are used for testing the performance of the antenna, and are given by:

$$
\left|H_{n, k}(f, d)\right|=\left|H_{c}\left(f^{n}, d^{k}\right)\right|
$$

In our application, we are focused on the frequency dependence of the path loss of the system made of the two identical antennas placed in different kinds of materials (such as sand for example). Then, $k=1$ is considered, and the frequency exponent $n$ is varied to analyze the behavior of the antenna.

The results, shown in Fig. 7, represent the transfer function of the system (transmitting antenna - free space channel $(n=$ $1)$ / path loss ( $n=1.5,2,2.5,3)$ - receiving antenna). One can notice the flat form of the result around the band of interest (6 $8.5 \mathrm{GHz}$ ), with a fluctuation of about $2 \mathrm{~dB}$, for $\mathrm{n}=1$ and 1.5 , which causes similar attenuation on all the frequency bandwidth of the signal, and then limits the distortion effect of the transmitted pulses. For the higher path loss order, the S21 results are decreasing with the increasing of both frequency and path loss order, which causes the deformation of the pulses and then get bad transmission.

Considering (8), in the case of free space $(n=1)$, the antenna transfer function is processed and represented in Fig. 8. We can note the increasing transfer function of the antenna on the band of interest, which allows compensating for the frequency dependency, caused by the free space transfer function which decreases with increasing of frequency. Thus, in the case of free space losses, this performance permits to get a flat channel transfer function, then getting better transmission.

In the case of more important path losses, the design of the antenna can be adapted, by properly varying the slots and parasitic element dimensions, to improve the antenna gain and then to overcome the propagation degradation.

\section{B. Time domain}

The time domain analysis is basically expressed by the fidelity factor and the stretch ratio for the different path losses scenarii exposed, and for the two pulses described.

The received impulse signals are distorted by the UWB antennas. To measure the degree of distortion, the fidelity factor $(F)$ is calculated [8]. It compares the transmitted and received impulse signals by mean of correlation calculation. The antenna presents the best performance when the fidelity factor is close to 1 , and the worst case is $F=0$.

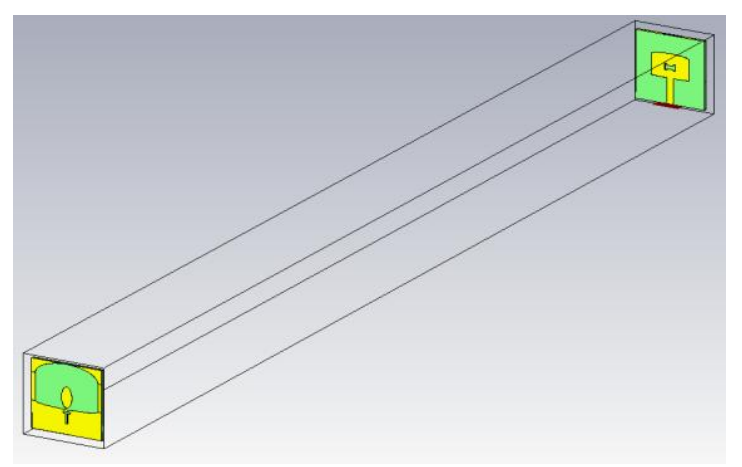

Fig.6. RF link frequency domain analysis.

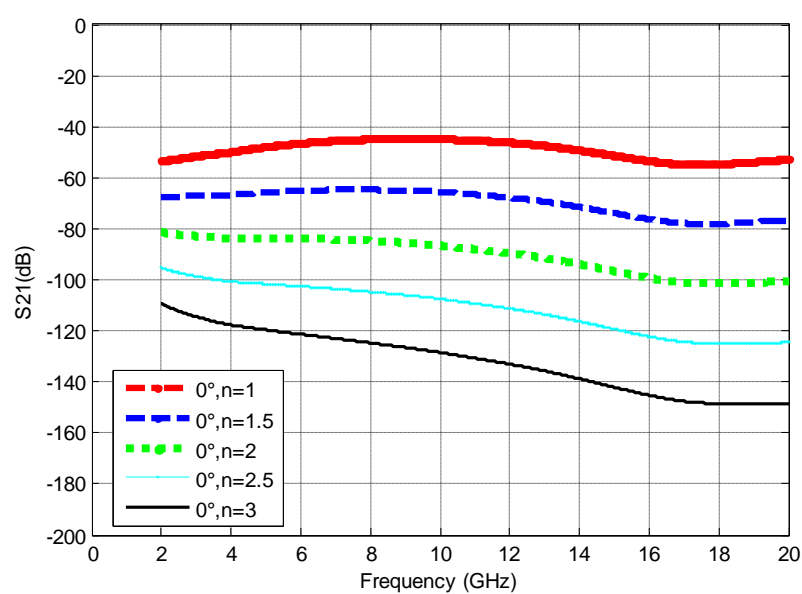

Fig. 7. Magnitude of $S 21: n=1,1.5,2,2.5$ and 3.

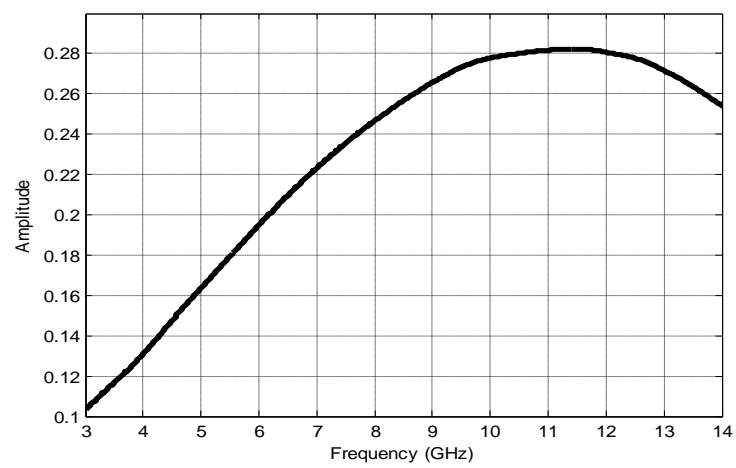

Fig. 8. Magnitude of antenna transfer function, from (8). 
Thus, the fidelity factor is given by:

$$
F=\max \frac{\left|R v_{r} v_{t}(\tau)\right|}{\sqrt{R v_{t} v_{t}(0) R v_{r} v_{r}(0)}}
$$

where $R v_{r} v_{t}(\tau)$ is the cross correlation of the transmitted and received signals, and $R v_{x} v_{x}(0)$ is the autocorrelation of the corresponding signal.

The considered pulses, presented in part I, (1) and (2), are reported in Fig. 9. For the studied antenna, Fidelity factors $(F)$ versus path loss order are given in Fig. 10. According to our results, it is noticed that the Fidelity factor, for both pulses, in free space channel $(n=1)$ is close to 1 (ideal transmission). For higher path loss order, the fidelity factor is decreasing with the increasing of path loss order, which means that the signal pulses are more distorted and then the transmission is degraded. The comparison between the two pulses Fidelity factors shows that the rectangular pulse is much more affected by the path loss effect. This is effectively due to the lowest and highest frequency component of the pulses spectra.

The time width of the transmitted impulse signal is of great importance: the smallest the pulse width, the higher the transmission data rate. However, UWB antenna causes width stretching to the transmitted waveform, which constrains the use of longer inter-pulse gaps that means decreasing of transmission rate and a widening of the pulse energy (less immunity to the noise for an energy receiver).

An evaluation of the pulse width stretching is necessary to determine the performance of the antenna. The parameter which allows assessing this phenomenon is the pulse width Stretch Ratio $(S R)$ [8]. The best performance of antenna is for $S R$ close to 1 , and it worsens with its increasing. The calculation of $S R$ is based on comparing energy distribution between the transmitted and received pulses. The pulse width can be defined as the width of the time window containing a $90 \%$ of the total energy. For a signal $v_{x}(t)$, let the normalized cumulative energy function $E_{v}(t)$ be defined by

$$
E_{v}(t)=\frac{\int_{-\infty}^{t}\left|v_{x}(\tau)\right|^{2} d \tau}{\int_{-\infty}^{\infty}\left|v_{x}(\tau)\right|^{2} d \tau}
$$

Then, the pulse width $W(v)$ for $90 \%$ energy capture is given by

$$
W(v)=E_{v}^{-1}(0.95)-E_{v}^{-1}(0.05)
$$

where $E_{v}^{-1}$ is the inverse function.

The pulse width stretch ratio $S R$ can be defined by the ratio of the width of the received waveform to the width of the transmitted waveform, as

$$
S R=\frac{W\left(v_{r}\right)}{W\left(v_{t}\right)}
$$

For the studied antenna, results of pulse width Stretch Ratio $(S R)$ versus path loss order are given in Fig.11. It is noted that the width Stretch Ratio of the proposed antenna, for both Gaussian and rectangular pulses, in free space channel $(n=1)$, is close to 1 , which means good performance of the antenna and non-dispersive behavior. For higher path loss order, the width

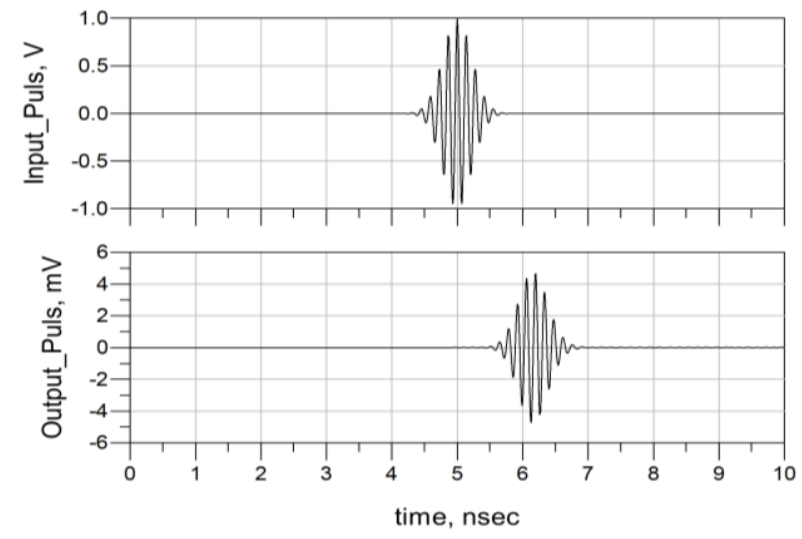

$-a-$

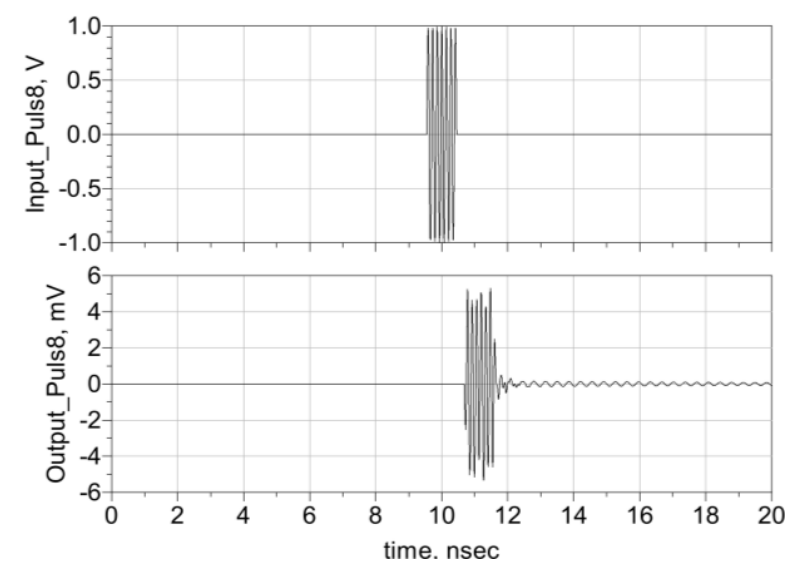

-b-

Fig. 9. UWB signals: (a) Gaussian transmitted/received pulses, (b) Rectangular transmitted/received pulses.

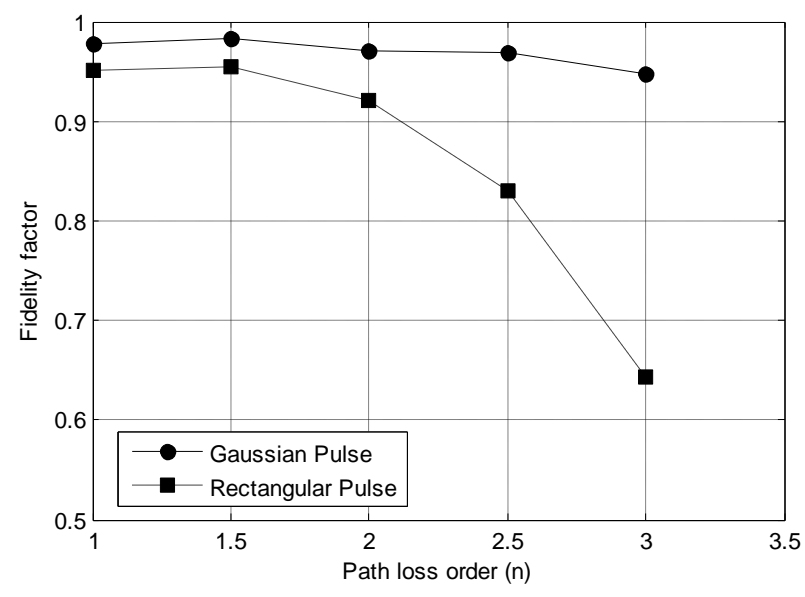

Fig. 10. Fidelity factor versus path loss order. 
Stretch Ratio increases. In the case of Gaussian pulse, the increase is not significant. In the case of a rectangular pulse, the Stretch Ratio is highly increasing with the path loss order $n$, which means a much more important stretching of the pulses and then decrease the complete system data rate. As some pulse generators are using a near pico-pulse generation technique, this result describes a strong potential degradation for such channels cases.

We propose also to evaluate the impact of the antenna on the pulse shape through an innovative metric: the kurtosis of the multi user interference. When many asynchronous Time Hopping Impulse Radio UWB users are active [15], they create multi user interference. It is known that due to the impulsiveness of the UWB signal, this interference is not Gaussian. The shape of the received pulse have an impact on the non-Gaussianity of the interference, it can be measured through the kurtosis. The further the kurtosis is from 0 , the less Gaussian are the interference. For the same power of interference, different kurtosis can be experienced, depending on the pulse shapes. It has been shown that the capacity of the communication (in bits per channel use) increase when the interference is less Gaussian if the appropriate receiver is used [16][17].

The way to compute the kurtosis and the respective capacity has been derived in [12]. We have computed it for the pulse shapes transmitted with our antennas and compared it with the theoretical Sholtz's pulse (second derivative of a Gaussian) [18] having the same bandwidth. The results are given in TABLE II.

We can note a slight variation of the kurtosis and of the capacity for the Gaussian filtered pulse in function of the propagation model and a very small loss with respect to the theoretical Sholtz's pulse. As expected, the rectangular filtered pulse is more affected by the change of the propagation model, while it Fidelity Factor was lowering, its transformation improve the kurtosis and thus the capacity.

\section{CONCLUSION AND FUTURE WORKS}

In this paper, a novel small planar monopole UWB antenna was presented and used in channels where the path loss was increased. The frequency and time FoM presented were selected regarding the dedicated application, which is the IRUWB communication in cluttered WSN. The proposed antenna has a huge bandwidth from $4.2 \mathrm{GHz}$ to $12.4 \mathrm{GHz}$ and an omnidirectional radiation pattern quantified by the isotropy factor. Its transfer function is increasing with frequency on the European UWB regulatory band and then compensates for the effect of free space channel propagation path loss attenuation.

With such dimensions, $20 \times 20 \times 0.8 \mathrm{~mm}^{3}$, the proposed antenna is potentially suitable for IR-UWB WSN applications.

The transmission of two signal pulses, Gaussian and rectangular, with such antennas and for several path loss order $(n=1,1.5,2,2.5$ and 3$)$ were studied, in order to determine the behavior of the antenna and its performances. The Fidelity and Stretch Ratio factors of the antenna, for both signal pulses, are respectively higher than $90 \%$ and lower than $5 \%$, for the free space channel $(n=1)$, which confirm its non-distortion behavior. The rectangular pulse is much more affected than the Gaussian pulse for the considered scenarii.

In this paper, we used some FoM matching with our applications and we quantify the performances of a proposed antenna. The pulse shape is of great interest during the conception and design of the dedicated antenna. The perspectives of our work are to customize this type of antenna in more precisely modeled cluttered WSN channel.

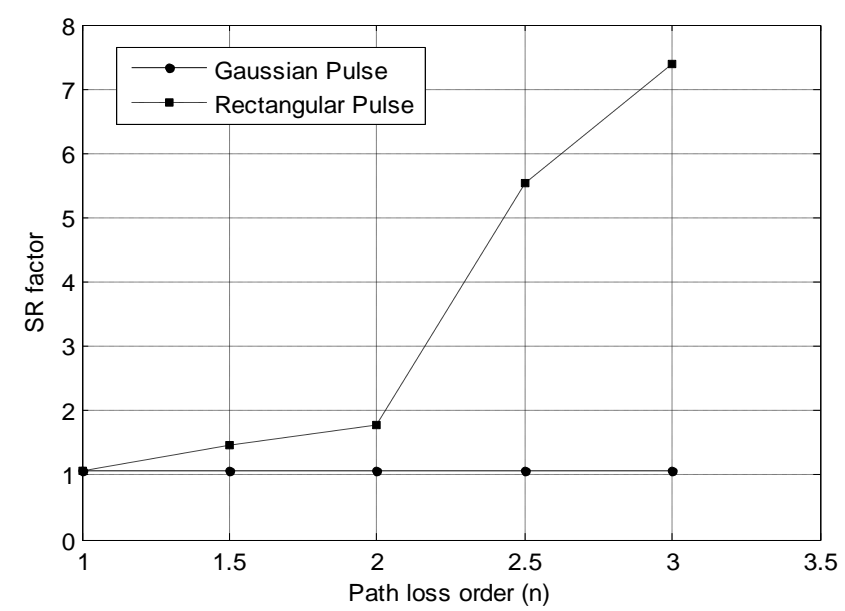

Fig. 11. Stretch Ratio versus path loss order.

TABLE II. Kurtosis and Capacity for various pulses, for TH-IR-UWB signals with perfect power control with 100 asynchronous users and a pulse rate of 10 Mega pluses per second (note that the Signal to Interference Ratio slightly depends on the pulse shape, it has not been reported here but it explains the non-monotonic behavior of the Capacity with respect to the kurtosis)

\begin{tabular}{|l|c|c|}
\hline \multicolumn{1}{|c|}{ Pulse } & Kurtosis & $\begin{array}{c}\text { Capacity in bits } \\
\text { per channel use }\end{array}$ \\
\hline Scholtz pulse & 2.06 & 0.77 \\
\hline $\begin{array}{l}\text { Gaussian filtered } \\
\text { pulse with n=1 }\end{array}$ & 1.8684 & 0.7514 \\
\hline $\begin{array}{l}\text { Gaussian filtered } \\
\text { pulse with n=3 }\end{array}$ & 1.8413 & 0.7413 \\
\hline $\begin{array}{l}\text { rectangular } \\
\text { filtered pulse with } \\
\text { n=1 }\end{array}$ & 1.484 & 0.7346 \\
\hline $\begin{array}{l}\text { rectangular } \\
\text { filtered pulse with } \\
\text { n=2 }\end{array}$ & 1.5379 & 0.7398 \\
\hline $\begin{array}{l}\text { rectangular } \\
\text { filtered pulse with } \\
\text { n=2.5 }\end{array}$ & 1.9204 & 0.8740 \\
\hline $\begin{array}{l}\text { rectangular } \\
\text { filtered pulse with } \\
\text { n=3 }\end{array}$ & 2.48 & 0.91 \\
\hline
\end{tabular}




\section{REFERENCES}

[1] Federal Communications Commission, "Revision of part 15 of the commission's rules regarding ultra-wideband transmission systems," First Report and Order, ET Docket 98-153, FCC 02-48, April 2002.

[2] W. Hirt, The european UWB radio regulatory and standards framework: Overview and implications, [ in Proc. IEEE Int. Conf. Ultra-Wideband, Singapore, 2007, pp. 733-738.

[3] M. Baghaei-Nejad, Z. Zou, H. Tenhunen, and L.-R. Zheng, "A novel passive tag with asymmetric wireless link for rfid and wsn applications," in Circuits and Systems, 2007. ISCAS 2007. IEEE International Symposium on, may 2007, pp. $1593-1596$.

[4] A. Toccafondi, D. Zampilli, C. Della Giovampaola, and V. Tesi, "Lowpower uwb transmitter for rfid transponder applications," in to appear on RFID-Technologies and Applications (RFID-TA), 2012 IEEE International Conference on, vol. 1, November 2012.

[5] S. Promwong, W. Hachitani, J. Takada, "Free space link budget evaluation of IR-UWB systems," Ultra Wideband Systems, 2004. International Workshop on Ultrawideband Systems and Technologies 2004 UWBST\& IWUWBS, pp.312- 316, 18-21 May, 2004.

[6] M. A. Peyrot-Solis and al. "State of the Art in UWB Antennas" $2^{\text {nd }}$ International Conf. on Electrical and Electronics Engineering (ICEEE), Mexico, Sept. 2005.

[7] M. Ghavami, L. Michael and R. Khono. "UWB signals and systems in communications engineering" Wiley 2004.

[8] Do-Hoon Kwon, "Effect of antenna gain and group delay variations on pulse-preserving capabilities of ultrawideband antennas," IEEE Transactions on Antennas and Propagation, vol.54, no.8, pp.2208-2215, Aug., 2006.

[9] H. Schantz. "The Art and Science of UltraWideBand Antennas" Artech House, 2005.

[10] A. Diet, N. Ribière-Tharaud. An "F-gain" antenna for UWB-RFID. Progress In Electromagnetics Research, PIER C, ISSN: 1937-8718, $\mathrm{N}^{\circ} 20$, pp. 111-123, 2011

[11] A. Diet, N. Ribière-Tharaud, “ Design and measurements of a quasiisotropic UWB planar antenna". Recent Patents on Electrical Engineering 2011,4, pp. 176-183, 2011.

[12] D. Panaitopol, J. Fiorina, A. Diet, N. Ribière-Tharaud. A New Criterion to Jointly Design the Antenna and Optimize the Communication Capacity in IR-UWB. PHY 6.1, IEEE Wireless Communications and Networking Conference WCNC, Budapest, may 2009, Hungary

[13] P.Pajusco, P.Pagani, "Frequency dependence of the UWB indoor propagation channel", The second Europeen Conference on Antennas and Propagation (EUCAP 2007) November 2007, Edinburgh, UK.

[14] A.M.J. Marindra, S. Promwong, J. Takada. "Comprehensive Characterization of a Novel UWB Elliptical Planar Monopole Antenna', TENCON 2012 - 2012 IEEE Region 10 Conference, 2012.

[15] M.-G. Di Benedetto, G. Giancola. "Understanding Ultra Wide Band, Radio Fundamentals", Upper Saddle River, New Jersey: Prentice Hall Pearson Education, Inc., 2004.

[16] J. Fiorina, D. Domenicali. "Revisiting TH-IR-UWB performance limits dependency on essential system parameters using the Generalized Gaussian Approximation" IEEE International Conference on Ultra Wideband (ICUWB'07), Singapore, Sept. 24-26 2007.

[17] J.Fiorina, D.Domenicali "The non validity of the gaussian approximation for multi-user interference in ultra wide band impulse radio: from an inconvenience to an advantage" IEEE Transactions on Wireless Communications, vol.8, November 2009, pages 5483-5489.

[18] M. Z. Win, R. A. Scholtz. "Impulse Radio: How it works", IEEE Communications Letters, vol.2, no.2, pp. 36-38, February 1998. 